\title{
Lessons Learned from
} Implementation of Information and Communication Technologies in Spain's Healthcare Services

\author{
Issues and Opportunities \\ J. Carnicero'; D. Rojas ${ }^{2}$ \\ 'Observatory of the National Health System. Ministry of Health and Social Policy; ${ }^{2}$ Spain; Independent Consultant, Spain
}

\section{Keywords}

eHealth, health information systems, information and communication technologies, ICT, electronic health records, EHR

\section{Summary}

Background: Spain's health services have undertaken a number of important projects aimed at the creation of Electronic Health Records (EHR) through the incorporation of Information and Communication Technologies (ICT) into patient care practices. The objective of this endeavor is to improve care quality and efficiency and increase responsiveness to the population's needs and demands. Between 2006-2009 over 300 million Euro were invested in projects of this type.

Objective: To better understand the success criteria, the difficulties encountered and certain issues that must be kept in mind to ensure successful implementation of ICT projects in health organizations, based on Spain's experiences in this field.

Methods: The projects' results are analyzed using the criteria of compliance with the expected scope, cost and time frame.

Results: The results can be considered satisfactory in primary care facilities, where almost $90 \%$ of Spain's general practitioners, pediatricians and primary care nurses are using electronic health record (EHR) systems. In hospitals EHR implementation is more uneven. Over $40 \%$ of Spanish primary care centers and $42 \%$ of pharmacies are using electronic prescription (the information system that connects the physician to the dispensing pharmacy and the dispensing pharmacy to the payer).

Discussion: All of Spain's health services are currently carrying out projects involving ICT application in healthcare, and a priori the benefits of ICT are not questioned. However, the costs and time frames required for these projects are clearly surpassing initial expectations, while the benefits perceived by both professionals and institutions remain limited. This situation may be due in part to the absence of a project management culture in the health services, which has led them to pay insufficient attention to the main difficulties and key issues related to the implementation of EHR.

\section{Correspondence to:}

Javier Carnicero

Observatory of the National Health System

Ministry of Health and Social Policy

Office 1605

Paseo del Prado 18-20

28014 Madrid

Spain

E-mail: jcarnicero@msps.es
Appl Clin Inf 2010; 1: 363-376

doi: 10.4338/ACl-2010-07-CR-0041

received: July 20, 2010

accepted: October 2, 2010

published: October 13, 2010

Citation: Carnicero J, Rojas D. Lessons Learned from Implementation of Information and Communication Technologies in Spain's Healthcare Services - Issues and Opportunities. Appl Clin Inf 2010; 1: 363-376

http://dx.doi.org/10.4338/ACI-2010-07-CR-0041 


\section{Introduction/Background}

Spain's National Health System (SNS) offers universal coverage and is financed by taxes. Healthcare is provided mainly in the public network of health services, with its 10,202 local health facilities, 2,916 health centers and 300 hospitals, which attend over 46 million inhabitants. It can thus be defined as an integrated public healthcare service. In addition to the public facilities, in Spain there are over 500 private hospitals, in which over $40 \%$ of the discharges are paid for by the public sector [1]. Healthcare in this country is organized in such a way that a clear distinction exists between the two levels of care. Primary health care is an integrated system composed of primary care centers (local health facilities and health centers) and multidisciplinary teams. This level provides services related to both personal and public health, with general practitioners playing the gatekeeper role in the SNS, as they are the patients' first point of contact with the system, except in the case of emergencies. Specialized care is provided by ambulatory polyclinics and hospitals. The two levels of care are usually managed through separate structures.

After a 25-year transition period from a centralized model in which legislation, planning and provision of health services were decisions of the national government, at the end of 2002 responsibility for health services was totally devolved to the regional level (Spain is comprised of 17 autonomous communities); this devolution resulted in 17 regional Ministries or Departments of Health with primary jurisdiction over the organization and delivery of health services within their territory, making Spain's system practically a federal one. Coordination of healthcare policy among the different communities and institutions is the task of the Interterritorial Council of the SNS, which is comprised of the 17 Regional Ministers of Health and the state government's Minister of Health and Social Policy.

The introduction of electronic health records in Spain began in the late 1990s, when this type of record started to be used by primary care doctors and some specific medical services in hospitals. However, major investment started in the early 2000s because the new regional administrations, which were eager to put in place innovative measures and differentiate themselves from each other, made great efforts to develop regional information systems and tools.

Between 2006 and 2009, the Healthcare Online Program, which forms part of the Quality Plan for the National Health System, invested over 300 million Euro in projects aimed at the application of Information and Communication Technologies (ICT) to healthcare, and in the next three years an investment of over 200 million Euro is foreseen. This Program is being carried out by the Secretary of State for Telecommunications and the Information Society in collaboration with the Ministry of Health and Social Policy and the autonomous communities [2].

\section{Objectives}

This paper reviews the current situation of the implementation of ICT in the Spanish healthcare system (electronic health records, electronic booking in primary care, and electronic prescriptions in primary care), in order to find out if the Healthcare Online Program and the EHR projects of the autonomous communities have fulfilled their objectives according to the success criteria (scope, time and cost). The paper also looks at the difficulties encountered in the implementation of health ICT in the Spanish healthcare system, and also the key issues that must be kept in mind to ensure the success of ICT projects in the health sector.

\section{Methods}

In 2007 the Spanish Health Information Society (SEIS) summoned 25 ICT and health services managers from different regions to a meeting for the purpose of analyzing the management of ICT projects in healthcare, and the difficulties encountered, and also to prepare a report on this topic. Although the object of the meeting was not the evaluation of the implementation of ICT in Spain, we have used the information obtained at that meeting [3], as well as information from our per- 
sonal experience as healthcare and ICT managers in the Spanish Health System, in the preparation of this paper.

In addition to this information we have reviewed the data published by Spanish central and regional authorities about the implementation of ICT $[1,2,4]$. The Annual Report of the Spanish National Health System [1] shows the functionalities of the EHR available in each region. The report from the Observatory for Telecommunications and the Information Society [2] is the main source of data about the diffusion of ICT in health services and the Review of Activities of the Quality Plan for the National Health System [4] reports on the advances towards interoperability among the different regions' systems.

\section{Results}

As shown in $>$ Table 1, in 2009 almost $90 \%$ of general practitioners, pediatricians and primary care nurses working in Spain use EHR on a regular basis in caring for patients, and most of them access hospital documents and receive the results of complementary tests in their computer. Electronic prescribing - the information system that connects the physician to the dispensing pharmacy and the dispensing pharmacy to the payer, which in this case is the health service - is broadly used in three of Spain's 17 autonomous communities and is being introduced in the rest. This means that about $40 \%$ of Spanish primary care centers and $42 \%$ of pharmacies are using electronic prescription. There are 12 million citizens ( $26 \%$ of the population) treated in primary care health centers with electronic prescription. Although $86 \%$ of patients are able to use Internet in order to make an appointment with their primary care doctor, just 3.28\% of appointments are made via Internet.

Information systems for hospital management - Hospital Information Systems, or HIS - have been commonly used since the beginning of the 1990s, and a clinical desktop is available in $70 \%$ of hospitals. Unfortunately there is no official data about actual utilization by doctors and nurses of EHR in hospitals. However, according to the Annual Report of Spanish National Health System [1], EHR developed by the various autonomous communities offer the main functionalities, such as computerized prescription, a medical orders system (test request and integration of results), vaccination register and clinical protocols. Some systems, such as laboratory management systems, are used regularly because they are departmental solutions provided by the suppliers of reactives and analysis equipment, although they often have the drawback of being closed solutions that present difficulties when it comes to evolving and integrating into larger systems. Other systems often used in hospitals are Radiology Imaging Systems (RIS) and Picture Archiving and Communication Systems (PACS) [2]. Many medical imaging projects were initially put in place in hopes of attaining a cost reduction, although they do offer valuable new possibilities, such as various departments working in partnership and teleradiology. Therefore, results obtained up through 2009 can be considered satisfactory $[2,4]$. The implementation of Electronic Health Records in primary care can be deemed a success, while implementation of ICT in hospitals is more uneven.

Although ICT projects have been undertaken independently by Spain's autonomous health services, the features of the various EHR are quite similar in all of them $[1,3]$. Despite the relative success of the EHR projects, some problems still need to be addressed:

- In general the final scope, time and cost do not coincide with initial expectations, for instance, several electronic prescriptions projects have not yet passed the pilot stage [2]. Moreover, 5 of 17 autonomous communities have not fully completed implementation of electronic medical orders, because some laboratory systems and medical reports are not yet integrated into the EHR [1].

- The solutions implemented are technologically and functionally different and not interoperable. This situation arises even among facilities in the same autonomous community.

- Clinical information cannot be accessed electronically from facilities in another autonomous community. This situation has begun to be corrected thanks to a project promoted by the Ministry of Health and Social Policy and the autonomous communities, which is included in the Healthcare Online Program. Currently there is a pilot project underway in two autonomous communities (Balearic Islands and Community of Valencia) that allows for the exchange of clinical information between the two health services. The first stage of this project has been the 
creation of a National Database of Health Cards, which integrates the regional databases. Another requirement specified in the project's objectives is the SNS Professional Registry, which at present is in the implementation phase $[1,4]$.

- There has been no systematic evaluation of the success or failure of the projects, or of the added value provided by ICT to the quality, effectiveness and efficiency of the health system, although this type of evaluation has been performed on certain projects $[5,6]$.

\section{Discussion}

\subsection{The project management triangle}

The three basic variables with which to define the success of any project are known as the project management triangle and correspond to the triple constraint [7] that governs the execution and delivery of a project: the outcome expected upon conclusion (scope), the amount of time available and the resources allocated (cost). ICT projects in the health sector are certainly no exception, as they too are affected by such constraints.

\subsection{Information available}

Unfortunately, the autonomous communities are not in the habit of publishing reports about the results of ICT projects in their health services. For this reason not much data is available. We have found only three official sources $[1,2,4]$ with information about the implementation of ICT in Spain. Although these data are mostly limited to the information summarized in $>$ Table 1 , they do give a good overview of the ICT advances in the Spanish Health System. Although the lack of more exhaustive data might be considered a limitation of this paper, it has been compensated to the extent possible by the direct knowledge of the authors and the information given by healthcare and ICT managers [3].

\subsection{Success criteria}

The scope, time frame and cost of a project clash against each other constantly, as any modification to one side of the triangle (considering as fixed the vertex opposite to that side) will necessarily have an impact on at least one of the other two, as shown in Figure 1. It is clear that broadening a project's scope will cause increases in its time frame, its cost or both (the latter as shown in the lower left example in Figure 1); shortening its time frame will generally bring about a reduction in the scope (as shown in the lower middle example in Figure 1); budget limitations may cause a reduction in a project's time frame, a reduction in its scope or both (the latter as shown in the lower right example in Figure 1 ). The discipline of project management lies in the capacity to organize the tasks that are to be carried out, while balancing the three existing constraints.

To appropriately define the scope of a project, the first stage is to perform a preliminary study that includes a viability assessment. If this assessment has a positive result, then the project requirements must be set forth clearly, concisely and completely in a Technical Specifications Sheet that defines the scope of the project. In the event that a market solution is deemed the best option, then the government bodies must begin the procedures related to the public invitation to tender and subsequent adjudication to a supplier. Our experience shows that once the project has been adjudicated, the scope is inevitably and continuously subject to all kinds of variations, by both the client and the supplier, during the various phases of execution (analysis, design, development, testing and implementation). These variations can be due to a number of causes: an incomplete preliminary study, erroneous drafting of the Technical Specifications Sheet, modifications in the client's requirements during project execution and supplier strategies, among others. The result of this client-supplier tension is sometimes the inclusion of new functionalities, the modification of planned functionalities or even the decision to do without some of the functionalities stipulated in the contract.

The time frame of a health ICT project is closely linked to the general strategy of the health services and is highly conditioned by the mandate of the heads of the public administration (legisla- 
tures) and also by the laws governing public administration contracts. Time is one of the main sources of conflict and disagreements between client and suppliers, and the established time frame is very seldom respected.

The cost of a project is the most deceptive of the three variables because, at least in the public administration, it is extremely difficult to determine the exact cost of a project. The usual tendency of upper-level management bodies is to consider the cost specified in the adjudication as the project's total cost, without taking into account the costs derived from its execution, of which the following are especially significant: the dedication of health system personnel, especially clinical staff, throughout the project; the acquisition of necessary hardware, software and communication infrastructure and the adaptation of existing ones, the contracting of support and maintenance services to ensure that the systems function normally at all times, and the evolution of the project's outcome, to adapt it to the needs that may arise in the future. Also, ICT projects have traditionally suffered from the absence of a specific budget allocation.

As explained above, the three variables (time frame, scope, and cost) are in no way independent from one another, since a modification to any of them will imply an adjustment to at least one, if not both, of the other two. Given their nature, time frame and cost are generally accorded greater importance, to the detriment of scope, which tends to suffer reductions with respect to the project's initial plans. An example of this can be found in electronic prescription in Spain. Due to budget difficulties and time constraints, in several autonomous communities this project has been put on hold while still in the early stages (pilot), although it has been successfully implemented in three autonomous communities [2].

\subsection{Difficulties}

Table 2 summarizes the various difficulties encountered and the key issues related to the projects undertaken by the health services of Spain. The execution of ICT projects in the healthcare sector runs into difficulties of various types from the very beginning. The first issue that must be addressed is the need to correctly identify the patient, the professional caring for him/her and the healthcare facility [8]. In Spain, the health services have dealt with this problem by using the same system as the one used to accredit the benefits to which patients are entitled; this system consists of each patient being assigned an individual health card. The creation of the National Health Card Database has been one of the main successes of the Healthcare Online Program [4].

However, not all the patients at health facilities have such an identifying card, and for this reason the health services of two autonomous communities (Cantabria and Balearic Islands) have developed specific systems for positive patient identification, which are valid wherever the person is in the care network. This system allows for the aggregation of the clinical information existing at different health facilities, thus guaranteeing patient care continuity.

A similar challenge is the need to correctly identify health professionals, as they are the ones responsible for accessing and maintaining the clinical information. Although reliable records regarding health professionals are available at each facility, it is also necessary that there be master files that allow for the identification of each professional at every point in the health service network. This need will be met by the SNS Professional Registry project, which is currently in the implementation phase [4].

Another fairly common situation is a high degree of dependence by the healthcare organizations on the suppliers of departmental solutions that already exist, such as those put in place by laboratories. This problem is, among other causes, the consequence of a lack of coordination and inefficient communication between health professionals and the ICT department managers and, subsequently, between these managers and suppliers. As a result, there can exist within a single institution several departmental solutions that are often incompatible with each other, which prevent the sharing of information between professionals, hinder continuity of care and bring about a considerable increase in costs. This circumstance explains the lack of full implementation of electronic medical orders in several autonomous communities [1].

These initial difficulties are often accompanied by problems of an organizational and technological nature, by problems related to implementing and managing change and by problems related to the management of suppliers and finances. 


\subsubsection{Organization, implementation and management of change}

The largest problem lies in the complexity of the healthcare organization, which arises from the fact that the care process is by definition personalized for each patient. This makes it very difficult to standardize the clinical act, which, furthermore, usually involves a high number of people and processes. Each health institution is comprised of different professional profiles [9] and has a structure of its own, which means the health services are extremely complex and of great magnitude. Herein lies another of the greatest difficulties in the execution of health ICT projects; the health record of each patient is the result of the aggregation of information recorded in each of the institutions in which that patient has received care (primary care centers, specialized care centers, emergency services, prevention services, among others). In order to share these data and make them available throughout the entire health system network, it is necessary to integrate all the information systems involved. Integration processes are very complex, because they entail establishing communication procedures and infrastructures between systems that are based on different technologies and architectures, using semantic and technological standards, identifying the patient correctly, implementing security and confidentiality measures, etc [8]. The two clearly established healthcare levels of Spain's National Health System explain the existence of at least two different medical records in several regions, one for primary care and another for specialized care, with no information sharing capabilities. In order to mitigate this problem many regions have developed projects whose aim is to allow access to records from different places and levels of care. Some of these projects pursue actual integration of records.

Another problem of the organizational type lies in the fact that clinical professionals must be involved in the execution of health ICT projects. In many cases professionals must combine ICT project tasks with their daily care activity [10], which means that priority conflicts often arise. In these situations, care activities tend to be given higher priority, to the detriment of ICT project tasks, which in the best of cases suffer slowdowns [3].

With regard to implementation, the start-up of the information systems put in place by the ICT project is always accompanied by the appearance of malfunctions that generate reluctance and loss of motivation in users and a temporary reduction in productivity [11], to the point, in the most extreme cases, of causing project failure and withdrawal of the system [12]. The main causes behind these malfunctions are varied.

The most important reason is perhaps the resistance to change by various members of the organization, from clinical staff to computer specialists to managers, who often want to avoid any modification in their work procedures, whether organizational, functional or technological. Their motives range from a sense of ownership and unwarranted esteem for the systems and methods currently in use, due to their personal participation in the creation or implementation of such systems and usually in association with their having a certain amount of power, to the refusal to assume the additional workload required by the new protocols and handling of the new tools. Since the early 2000s all new hospitals built in Spain have incorporated EHR from the very beginning (they are colloquially known as "hospitales sin papeles" - paperless hospitals), however the process is much more difficult in older hospitals because they use legacy systems and have old processes [14]. A different example is the on-line appointments service. Although this service is available for $86 \%$ of the population, only $3.28 \%$ of the appointments were booked on-line in 2009 . Possible causes for this poor result are resistance to change by either administrative assistant staff or citizens. Administrative staff might reject any change in their current work procedures, and might even be afraid of losing their jobs in the event that this service becomes fully automated, and in such a case they would not encourage the use of the on-line service. In the case of patients, the fine performance to date of the existing call center for telephone booking of appointments, along with uneven usage of Internet by citizens (it being more extended among the younger population) might explain the limited use of the Internet booking service.

Another frequent cause of problems is last-minute inclusion of new requisites that have not been properly evaluated, right before system start-up takes place. We believe that this situation is often the consequence of the lack of participation of clinical professionals from the beginning of the project, something of vital importance since they will be the final users of the systems being introduced [3]. 
Also common are the absence of appropriate technical support during the first few days of system operation, frequently the result of bad planning, and inadequate advance training, due to the previously discussed difficulty that clinical professionals face in combining their daily care activity with project participation. One of the most important consequences of insufficient training is a sense of insecurity in clinical professionals regarding data protection and the confidentiality of the information.

\subsubsection{Technology}

With regard to technical issues, the main problem lies in the need to ensure information quality based on the existence of a single version of each data element (the uniqueness of data principle) that is accessible from multiple locations, given the difficulty of achieving interoperability among the different information systems already in existence. This is usually due to the nonexistence of the necessary system integration among them, and to the fact that in some cases such integration may be unviable because of the use of closed technologies that are owned by the corresponding supplier. To address the aforementioned need, many health services are adopting open standards for the exchange of clinical information through messaging and are renovating their technological platforms for the development and operation of software applications and for database management, which of course involves subsequent maintenance activities. Sharing information from different EHR systems in different autonomous communities is one of the purposes of the Healthcare Online Program [4], which is in the preliminary (pilot) stages. The continuous and rapid advance of technology represents an added difficulty, one that makes it necessary to create and follow training and skill update programs for the professionals who comprise the technical teams in the health services.

\subsubsection{Management of suppliers}

In the area of project planning and management, Spain's health services are highly conditioned by legislation the aim of which is not to guarantee the project's efficacy and efficiency but rather its transparency, competitiveness and the guarantee of equal opportunities among suppliers. This leads to contracting procedures that are very complex and generally inefficient and ineffective, which greatly complicates the long-term planning and management of projects, such as those that require the application of ICT in healthcare.

Once the project has begun, it often proves difficult to reconcile the interests of suppliers with those of the client, in this case the health services [3].

\subsubsection{Investment and costs}

In the field of finances, the first problem, as mentioned above, is that it is practically impossible to calculate the real cost of a project, due to uncertainty and changes in the project, unbudgeted costs, such as those derived from the allocation of internal resources, or opportunity costs. All of this is exacerbated by the immediacy of costs and the delay in obtaining benefits, which are always seen as doubtful from the long-term and financial point of view. This generally means that the return on investment is frequently questioned by the organization. Finally, investment in ICT is deeply affected by economic cycles, it being one of the first items to suffer cutbacks in periods of economic crisis like the current one.

\subsection{Lessons learned}

\subsubsection{Organization, implementation and management of change}

Projects involving the application of health ICT require strategic planning that is directly linked to and coherent with the organization's general strategy and that clearly states the actions to be undertaken, always keeping in mind the complexity and priorities of healthcare institutions. In other words, the ICT strategy should be the consequence of the health system's strategy. This is the only way that the ICT solutions developed will respond appropriately to the needs of the organization, be considered an effective and necessary instrument for reaching the objectives set for it and receive the institutional, clinical, technical and budgetary support they need.

Before a project is begun, it is of fundamental importance that a study on the organization's processes be conducted, paying special attention to the issue of interoperability among them [13], since the technology itself is not the cause of most problems, but rather the tool that makes pre- 
existing problems become visible. If a process is ineffective or inefficient, its transfer to the ICT sphere will be, too [14]. As explained earlier, an ICT project is more than a technological project; it is a strategic initiative for the organization and should thus be in line with its corporate values.

It is crucial to determine the added value that the execution of these projects will bring, and transmit it both to professionals and to the directors of the organization, with special emphasis being placed on the new utilities that arise thanks to the incorporation of the technologies. This will make it easier to overcome the resistance to change often shown by users.

Another organizational aspect of fundamental importance is leadership at the different levels of the health system, from the directors of the health service through each center or facility, and especially in each specific ICT project [15]. The ideal leadership figure is a clinical professional who has the functional knowledge necessary to execute the project, who is well-known and respected by his/her colleagues and who has the firm and decisive support of the directing bodies, which allow this person to make decisions, and who can avoid conflicts that may result in rejection of the project by users. Herein lies one of the greatest weakness of organizations; it is, in our experience, very difficult to find a person with all of these qualities. Such difficulty compels organizations to choose the leaders and working groups that are most similar to this profile, yet because they are in scarce supply, the same leaders tend to be chosen for the different projects and situations of dependence often develop.

To ensure the success of the measures discussed in this section, the ICT strategy must be presented formally to the entire organization [16], clearly setting forth the lines of strategy to be used, the objectives sought, the working groups, the designated leaders and the management/coordination model that everyone must follow during the execution of this strategic plan. For this to occur, it is vital that there be continuous and explicit support by the service directors, who must assume ownership of the projects and transmit this idea to all of the organization's professionals, since one of the keys of success is the participation of all the involved parties. Likewise, a receptive, flexible and patient attitude must be shown with regard to the proposals made by each member of the working groups to the others, to help maintain motivation and enthusiasm in the project participants. In fact, adding minor functionalities and utilities not included in the scope as initially defined can facilitate the project's development and its degree of acceptance by users [3].

Finally, once the initial difficulties have been overcome, it is necessary to put in place dynamics that allow for continual improvement in the processes and systems [17], in order to fine-tune and adapt them to the needs that arise at any given time.

\subsubsection{Technology}

The technological platform that is to be used must be defined at the beginning of the project. It is important to keep in mind that the new systems will co-exist with the legacy systems, and that the latter tend to use departmental, commercial and closed solutions, which, along with the absence of standards, makes it very difficult to achieve the integration of legacy and future information systems. Also, once the technological platform has been chosen, the technical professionals at the health services must receive the necessary training.

During project execution, it is essential that the software designed suit users' needs perfectly and that it incorporate, wherever possible, their suggestions [18]. However, perfection is an ideal that will not be the same for all stakeholders, since each of them will have a different vantage point in the project. Thus, assessment is necessary to ensure that there is as close a match as possible between users' needs and system features. The systems must be interoperable to ensure quality information based on the uniqueness of data principle, integrating information in a structured, secure and simple way, and using intuitive interfaces that are user-friendly [8]. Also, there must be continuous monitoring and assessment of the project's development [19], paying special attention to the implementation phase, in which it is very important to do a pilot test that is suitably limited yet representative, in a controlled area [20], and also to have the time and resources to carry out the various concurrent activities prior to system start-up [10]: tests examining its functionality and interoperability with other systems, debugging, data migrations, user training, organizational and procedural changes, etc. Along the same lines, once the objectives of the pilot have been reached, the system must rapidly be expanded to the rest of the organization, so as to minimize the coexistence of old and new systems. Our experience with pilots that are not quickly refined and expanded 
shows that afterwards it is much more difficult to continue with the project. Moreover, our experience indicates that if the project requires that users test the functionality several times, because it repeatedly incorporates changes and thus calls for new testing, with the consequential delay in the final solution, the project runs a high risk of failure because users tend to become demoralized.

\subsubsection{Management of suppliers}

A final key element in the execution of projects is the supplier. Because it is external, its objectives do not totally coincide with those of the organization, and this is one of the most common causes of disagreements, conflicts and delays in execution. However, the supplier is yet another participant in the project and its commitment to the organization and its support during the development, implementation, maintenance and evolution of systems are necessary. For this to happen, the supplier must assign a working team that is highly-capable and stable over time, and it must collaborate closely with the organization in the monitoring and management of risks related to the project, keeping in mind the fact that problems are always shared and that their appearance is useful for measuring the flexibility and response capacity of both parties.

The ICT projects undertaken in Spain's health system, which require large investments and long execution periods, must no longer be based on the classic supplier-client relationship. New formulas must be found that allow suppliers and health services to work in association with each other, sharing in both the risks and the benefits of the projects, and to collaborate on the maintenance and evolution of the systems.

\subsubsection{Investment and costs}

Investment in ICT must be considered just another one of the investments that the health system has to make. As do all investments, it requires the budgeting of all related costs, including system maintenance and evolution. In addition, the benefits must be evaluated, both strictly economic ones and also improvements in service efficacy, efficiency and quality. ICT are yet another tool used by the healthcare system and it is no longer possible to conceive of a functioning health sector without the use of such technologies. That is why ICT must be part of the health system's budget, just like any other technology used in healthcare. The size of their budget allocation will depend on the importance accorded to them in the strategy used by the health system.

\section{Conclusions}

The execution of ICT projects in the healthcare sector is a difficult task requiring much time and effort, and success depends on following the courses of action set forth below, among others:

- The health service must draw up an ICT strategic plan in connection with the health system's general strategy. Projects involving ICT application are not exclusively technological.

- It is important to take into account the high degree of complexity of health institutions, as well as the fact that they cannot stop their care activity at any time and, further, such activity is of higher priority than the ICT projects.

- It is necessary that a realistic time frame be established and that there be appropriate allocation of human, material and budgetary resources at the internal level, in addition to external contracting.

- The plan must be defined and officially presented, along with the working groups and the work methods to be used.

- The ongoing commitment of the supplier is essential for effective project development.

- Participation, coordination and leadership are basic to the success of the projects.

- Change management must be based on the new system's added value, reliability and quality, in listening to and training users, and in the patience shown by working groups.

- The technological platform must be open, easily scalable, user-friendly and understood by the organization's own technical staff.

- The new systems must integrate fully and efficiently with the legacy systems, to ensure information quality.

- Implementation must begin in a controlled manner, with a pilot study limited to a specific area, and then expand rapidly, minimizing the coexistence of the new systems and the preceding ones. 
- Health ICT projects never come to an end and therefore plans must be made for the necessary maintenance, support and evolution services.

- Health authorities should publish their ICT plans, stating their scope, cost and time frames. They should also systematically evaluate the success of those plans, according to these criteria, in order to learn the necessary lessons to improve subsequent projects.

Adhering to this list of best practices will help health services to create a corporate culture that is conducive to the successful management and execution of projects involving the application of health ICT, allowing clinical professionals to offer patients higher quality care and thus making patients the primary beneficiary.

\section{Acknowledgements}

The authors wish to thank Óscar Blanco, Ignacio Elicegui and Raúl Martínez for their valuable comments and contributions to this paper.

\section{Conflicts of interest}

The authors declare that they have no conflicts of interest regarding the contents of this paper and that this paper reflects the personal opinions of its authors and not the position of the Observatory of the National Health System (Quality Agency of Spain's Ministry of Health and Social Policy).

Protection of Human Subjects and Animals in Research

The authors declare that no human subjects were involved in the project. 


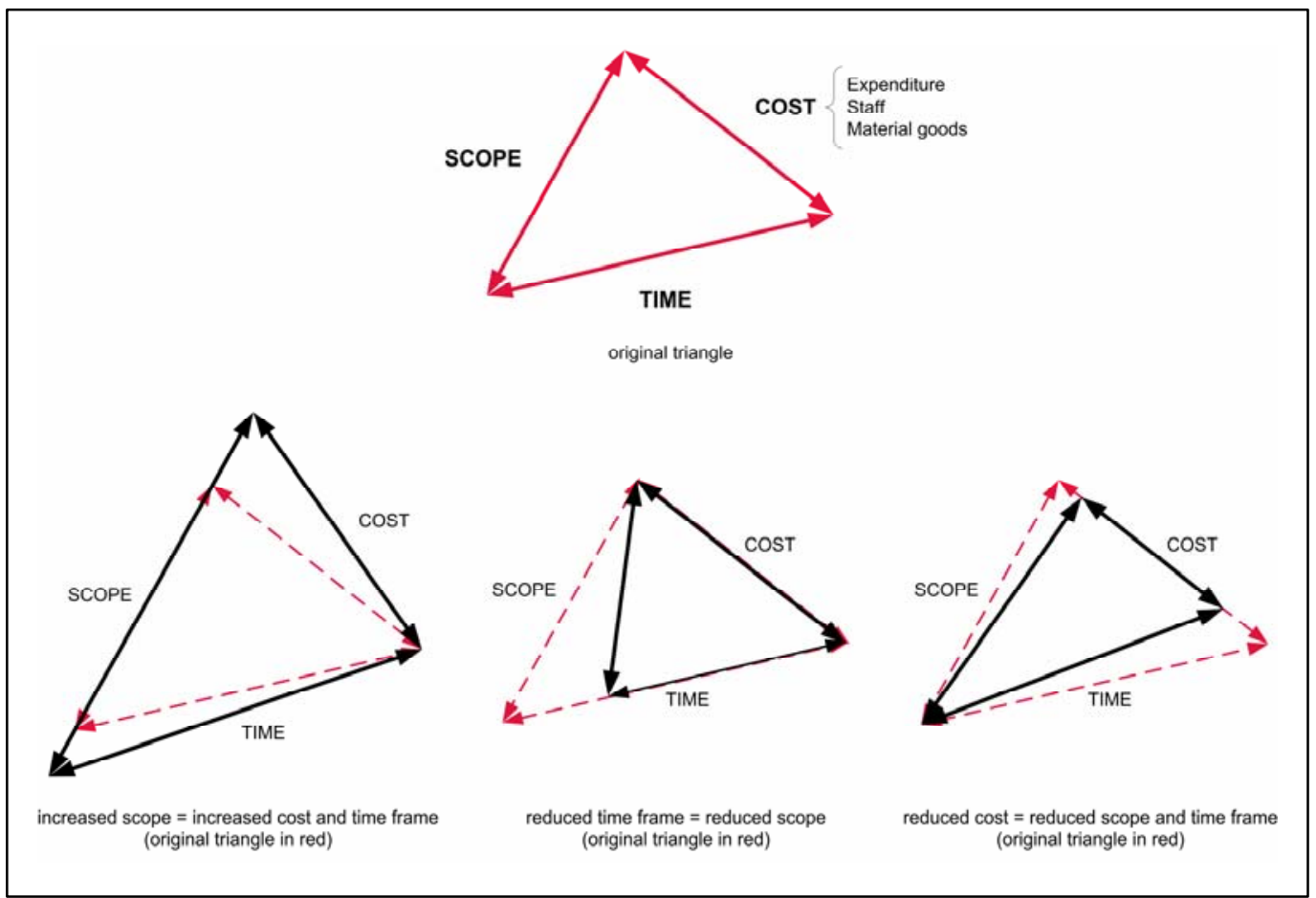

Fig. 1 Project management triangle 
Table 1 ICT and Electronic Health Records in the Spanish National Health System (2007-2009). Data from the National Observatory for Telecommunications and the Information Society [2]

\begin{tabular}{|c|c|c|}
\hline Electronic health record & 2007 (1) & 2009 (1) \\
\hline Primary care centers with Electronic Health Records & (2) & $3,718(98 \%)$ \\
\hline General practitioners using Electronic Health Records & (2) & $28,163(88 \%)$ \\
\hline $\begin{array}{l}\text { Hospitals with electronic patient management and clinical desktops } \\
\text { available }\end{array}$ & (2) & $226(70 \%)$ \\
\hline Electronic booking in primary care & 2007 & 2009 \\
\hline Primary care centers with on-line appointments service & $2,282(65 \%)$ & $3,321(87 \%)$ \\
\hline Citizens registered in centers with on-line appointments service & $22,082,166(55 \%)$ & $37,116,767(86 \%)$ \\
\hline On-line appointments in primary care & $5,289,677(1.5 \%)$ & $12,464,018(3.28 \%)$ \\
\hline Electronic prescription in primary care (3) & 2007 & 2009 \\
\hline Primary care centers in which computerized prescription is available & $3,338(95 \%)$ & $3,718(98 \%)$ \\
\hline Primary care centers in which electronic prescription is available & $420(12 \%)$ & $1,513(40 \%)$ \\
\hline Pharmacies in which electronic dispensing is available & $3,489(18 \%)$ & $8,879(42 \%)$ \\
\hline $\begin{array}{l}\text { Citizens treated in primary care centers in which electronic prescription } \\
\text { is available }\end{array}$ & $7,199,906(18 \%)$ & $11,999,298(26 \%)$ \\
\hline Prescriptions dispensed accessing electronic prescription system & $24,788,288(3 \%)$ & $139,383,324(18 \%)$ \\
\hline \multicolumn{3}{|c|}{$\begin{array}{l}\text { (1) The percentage is the proportion of each item of data in relation to the Spanish total } \\
\text { (2) Data not available } \\
\text { (3) Computerized prescription is the use of electronic health record systems that allow general practitioners to print } \\
\text { prescription data on paper and give it to the patients. Electronic prescription is the information system that connects } \\
\text { the physician to the dispensing pharmacy and the dispensing pharmacy to the payer, which in this case is the health } \\
\text { service }\end{array}$} \\
\hline
\end{tabular}


Table 2 Difficulties and key issues related to ICT projects in healthcare systems

\begin{tabular}{|c|c|}
\hline Initial difficulties & $\begin{array}{l}\text { - Need to identify the patient and the healthcare professional correctly } \\
\text { - High degree of dependence on the suppliers of solutions already being used }\end{array}$ \\
\hline \multicolumn{2}{|c|}{ Organization, Implementation and Management of Change } \\
\hline Difficulties & $\begin{array}{l}\text { - High degree of complexity of care activity and of healthcare organizations } \\
\text { - Aggregation of distributed information to create patient's EHR } \\
\text { - Simultaneity of care activity and ICT project execution } \\
\text { - Limited time available to clinical professionals } \\
\text { - Appearance of malfunctions following the start-up of information systems } \\
\text { - Reluctance and loss of motivation by users } \\
\text { - Initial decrease in productivity } \\
\text { - Resistance to change } \\
\text { - Need for effective technical support } \\
\text { - Insufficient or inadequate training of users } \\
\text { - Fears regarding information security }\end{array}$ \\
\hline Key issues & $\begin{array}{l}\text { - ICT strategic plan as part of the health system's general strategy } \\
\text { - Preliminary study of organization's processes } \\
\text { - Search for added value } \\
\text { - Leadership and participation of clinical professionals } \\
\text { - Formal presentation of project, objectives, working groups and methods } \\
\text { - Receptive, flexible and patient attitude } \\
\text { - Dynamics that allow for ongoing improvement following start-up }\end{array}$ \\
\hline \multicolumn{2}{|l|}{ Technology } \\
\hline Difficulties & $\begin{array}{l}\text { - Information quality and data uniqueness } \\
\text { - Interoperability problems due to non-existence of integration among systems } \\
\text { - Existence of market solutions of a closed nature } \\
\text { - Renewal and maintenance of the technological platform used } \\
\text { - Ongoing training of internal technical staff }\end{array}$ \\
\hline Key issues & $\begin{array}{l}\text { - Definition of technological platform } \\
\text { - Planning for the coexistence of new systems and legacy systems } \\
\text { - Interoperability } \\
\text { - Design and development of intuitive and user-friendly software } \\
\text { - Ongoing monitoring and evaluation of the project } \\
\text { - Limited but representative pilot study } \\
\text { - Availability of time and resources necessary to prepare for the start-up } \\
\text { - Rapid post-pilot expansion }\end{array}$ \\
\hline \multicolumn{2}{|c|}{ Management of Suppliers } \\
\hline Difficulties & $\begin{array}{l}\text { - Complex, ineffective and inefficient contracting procedures } \\
\text { - Interests of supplier different from those of the healthcare organization }\end{array}$ \\
\hline Key issues & $\begin{array}{l}\text { - Supplier support for implementation and start-up } \\
\text { - Highly-capable work team that is stable over time } \\
\text { - Flexibility and response capacity when common problems arise } \\
\text { - Collaboration between supplier and organization beyond the implementation } \\
\text { (maintenance and evolution) }\end{array}$ \\
\hline \multicolumn{2}{|c|}{ Investment and Costs } \\
\hline Difficulties & $\begin{array}{l}\text { - Impossibility of calculating real cost of the projects } \\
\text { - Immediacy of costs versus delay in seeing benefits } \\
\text { - Doubt regarding return on investment }\end{array}$ \\
\hline Key issues & $\begin{array}{l}\text { - Investment, development, maintenance and evolution must all be budgeted } \\
\text { - Benefits must be appraised in economic terms and also in terms of quality } \\
\text { improvement } \\
\text { - ICT must be considered one of many healthcare technologies }\end{array}$ \\
\hline
\end{tabular}




\section{References}

1. Spanish Ministry of Health and Social Policy. National Health System of Spain Annual Report 2008. Madrid: Ministry of Health and Social Policy 2010; 464 p.

2. National Observatory for Telecommunications and the Information Society. Information and Communication Technologies in the National Health System Report. Madrid: Spanish Ministry of Industry, Tourism and Commerce 2010; $26 \mathrm{p}$.

3. Carnicero J, compiler and editor. La gestión de proyectos de tecnologías de la información y de las comunicaciones en los servicios de salud - Informe SEIS (7). Pamplona: Sociedad Española de Informática de la Salud 2007; 272 p.

4. Spanish Ministry of Health and Social Policy. Report: Quality Plan For The National Health System of Spain 2006-2010 - Review of activities to date and summary of future actions. Madrid: Spanish Ministry of Health and Social Policy 2010; 68 p.

5. Montesino M, González AS. Historia clínica informatizada: 8 años de experiencia en un servicio médico quirúrgico. Rev Calid Asist 2010; 25(3): 173-180.

6. González E, Pérez F. La historia clínica electrónica. Revisión y análisis de la actualidad. Diraya: la historia de salud electrónica de Andalucía. Rev Esp Cardiol Supl 2007; 7: 37C-46C.

7. Project Management Institute. A Guide to the Project Management Body of Knowledge (PMBOK Guide). 4th ed. Newtown Square (PA): Project Management Institute 2008; 459 p.

8. Carnicero J, Blanco O, Mateos M. The application of information and communication technologies to clinical activity: Electronic health and clinical records. Pharmaceuticals Policy and Law 2005-2006; 8 6982.

9. Callen JL, Braithwaite J, Westbrook JI. Contextual Implementation Model: A Framework for Assisting Clinical Information System Implementations. J Am Med Inform Assoc 2008; 15: 255-262. doi: 10.1197/jamia.M2468.

10. Trivedi $\mathrm{MH}$ et al. Barriers to implementation of a computerized decision support system for depression: an observational report on lessons learned in "real world" clinical settings. BMC Medical Informatics and Decision Making 2009; 9: 6. doi:10.1186/1472-6947-9-6.

11. Poissant L, Pereira J, Tamblyn R, Kawasumi Y. The Impact of Electronic Health Records on Time Efficiency of Physicians and Nurses: A Systematic Review. J Am Med Inform Assoc. 2005; 12: 505-516. doi: 10.1197/jamia.M1700.

12. Bates DW. The road to implementation of the electronic health record. Proc (Bayl Univ Med Cent) 2006; 19: 311-312.

13. Zandieh $\mathrm{SO}$ et al. Challenges to EHR Implementation in Electronic- Versus Paper-based Office Practices. J Gen Intern Med 2008; 23(6): 755-761. doi: 10.1007/s11606-008-0573-5.

14. Lium JT, Tjora A, Faxvaag A. No paper, but the same routines: a qualitative exploration of experiences in two Norwegian hospitals deprived of the paper based medical record. BMC Medical Informatics and Decision Making 2008; 8: 2. doi:10.1186/1472-6947-8-2.

15. Terry AL et al. Implementing electronic health records: Key factors in primary care. Can Fam Physician 2008; 54: 730-736.

16. Shekelle PG. Implementation of health information technology: an important but challenging field of inquiry. Proc (Bayl Univ Med Cent) 2006; 19: 313.

17. McGowan JJ, Cusack CM, Poon EG. Formative evaluation: A critical component in EHR implementation. J Am Med Inform Assoc 2008; 15: 297-301. doi: 10.1197/jamia.M2584.

18. Doebbeling BN, Pekny J. The Role of Systems Factors in Implementing Health Information Technology. J Gen Intern Med 2008; 23(4): 500-501. doi: 10.1007/s11606-008-0559-3.

19. Lorenzi NM, Kouroubali A, Detmer DE, Bloomrosen M. How to successfully select and implement electronic health records (EHR) in small ambulatory practice settings. BMC Medical Informatics and Decision Making 2009; 9: 15. doi:10.1186/1472-6947-9-15.

20. Fullerton $\mathrm{C}$ et al. Lessons learned from pilot site implementation of an ambulatory electronic health record. Proc (Bayl Univ Med Cent) 2006; 19: 303-310. 